\title{
From two competing oscillators to one coupled-clock pacemaker cell system
}

\author{
Yael Yaniv ${ }^{1 *}$, Edward G. Lakatta ${ }^{2 *}$ and Victor A. Maltsev ${ }^{2}$ \\ 'Biomedical Engineering Faculty, Technion-IIT, Haifa, Israel \\ ${ }^{2}$ Laboratory of Cardiovascular Science, Biomedical Research Center, Intramural Research Program, National Institute on Aging, National Institutes of Health, \\ Baltimore, MD, USA
}

\section{Edited by:}

Ming Lei, University of Oxford, UK

\section{Reviewed by:}

Sandeep Pandit, University of

Michigan, USA

Oleg Aslanidi, King's College

London, UK

\section{*Correspondence:}

Yael Yaniv, Biomedical Engineering Faculty, Technion-IIT, Technion City, Haifa 3200003, Israel

e-mail: yaely@bm.technion.ac.il;

Edward G. Lakatta, Laboratory of

Cardiovascular Science, Biomedical

Research Center, Intramural

Research Program, National Institute on Aging, National Institutes of

Health, 251 Bayview Blvd, Baltimore

21224, MD, USA,

e-mail: lakattae@grc.nia.nih.gov
At the beginning of this century, debates regarding "what are the main control mechanisms that ignite the action potential (AP) in heart pacemaker cells" dominated the electrophysiology field. The original theory which prevailed for over 50 years had advocated that the ensemble of surface membrane ion channels (i.e., "M-clock") is sufficient to ignite rhythmic APs. However, more recent experimental evidence in a variety of mammals has shown that the sarcoplasmic reticulum (SR) acts as a " $\mathrm{Ca}^{2+}$-clock" rhythmically discharges diastolic local $\mathrm{Ca}^{2+}$ releases (LCRs) beneath the cell surface membrane. LCRs activate an inward current (likely that of the $\mathrm{Na}^{+} / \mathrm{Ca}^{2+}$ exchanger) that prompts the surface membrane "M-clock" to ignite an AP. Theoretical and experimental evidence has mounted to indicate that this clock "crosstalk" operates on a beat-to-beat basis and determines both the AP firing rate and rhythm. Our review is focused on the evolution of experimental definition and numerical modeling of the coupled-clock concept, on how mechanisms intrinsic to pacemaker cell determine both the heart rate and rhythm, and on future directions to develop further the coupled-clock pacemaker cell concept.

\section{Keywords: arrhythmias, coupled-clock pacemaker system, heart rate variability, mathematical modeling, sinoatrial node}

\section{INTRODUCTION}

Under normal conditions, specialized, self-excitable pacemaker cells within the sinoatrial node (SAN) initiate the spontaneous action potentials (AP) that are conducted to the ventricle to entrain the rate and rhythm of ventricular myocytes contractions. The identities and the relative roles of the control mechanisms within heart pacemaker cells that ignite the AP have been debated for more than 50 years. The predominant theory later named "M-clock" advocated that the ensemble of surface membrane ion channels was sufficient to ignite spontaneous AP (reviewed in Maltsev et al., 2006). This concept promoted decades of extensive voltage-clamp studies that have led to identification of numerous ion-current components in pacemaker cells (reviewed in Wilders, 2007): L-type $\mathrm{Ca}^{2+}$ current $\left(\mathrm{I}_{\mathrm{Ca}, \mathrm{L}}\right)$, outward- $\mathrm{K}^{+}$currents $\left(\mathrm{I}_{\mathrm{K}}\right)$, etc. Importantly, some but not all investigators concluded that a hyperpolarization-activated "funny" current $\left(\mathrm{I}_{\mathrm{f}}\right)$, is the dominant M-clock current driving early diastolic depolarization. However, since the time of $\mathrm{I}_{\mathrm{f}}$ discovery its major role in cardiac pacemaking was challenged (Vassalle, 1995) and further experimental and theoretical results led to an extensive debate on the role of $\mathrm{I}_{\mathrm{f}}$ (reviewed in Maltsev and Lakatta, 2012). In the late 1980s, experimental evidence began to emerge on the role of $\mathrm{Ca}^{2+}$ in pacemaker function under normal physiologic conditions (for more details see Maltsev et al., 2006). Subsequent studies discovered that sarcoplasmic reticulum (SR), a major $\mathrm{Ca}^{2+}$ store, can spontaneously and rhythmically oscillate $\mathrm{Ca}^{2+}$ uptake and release forming additional oscillator mechanism in pacemaker cells, termed $\mathrm{Ca}^{2+}$-clock. $\mathrm{Ca}^{2+}$-clock together with the M-clock form the modern concept that coupled-clock pacemaker system controls the cardiac pacemaker cell function.

To ignite an AP, the $\mathrm{Ca}^{2+}$-clock communicates with the Mclock via multiple $\mathrm{Ca}^{2+}$ and voltage-dependent mechanisms (discussed below). Nevertheless, one approach to gain further insights into the systems operation has been to artificially split the two clocks into two separate competing mechanisms (see for example Noble et al., 2010). A major consequence of such approach let to a continuing debate about which clock or pacemaker mechanism is dominant, and which one is minor (i.e., being a follower or entrained) (Lakatta and Difrancesco, 2009; Rosen et al., 2012). An alternative view is that both intracellular and sarcolemmal mechanisms are dynamically and synergistically coupled to each other (Figure 1), and the degree of the coupling determines the normal pacemaker function (Lakatta et al., 2010). This view, known as a coupled-clock theory, is based on the results of numerical modeling (Maltsev and Lakatta, 2009, 2010, 2013) and verified by experimental data (Yaniv et al., 2013a, 2014b). Therefore, a modern view on the cardiac pacemaker cell function is that neither clock is dominant; rather it is the coupled-clock system that controls the pacemaker cell AP firing rate and rhythm.

\section{MECHANISMS INTRINSIC TO PACEMAKER CELL DETERMINE THE COUPLED-CLOCK RATE}

After more than 50 years of research it is apparent that the pacemaker function is orchestrated via intrinsic signaling mechanisms originating at multiple levels of organization, including subcellular (e.g., phosphorylation cascades, SR, mitochondria), cellular 


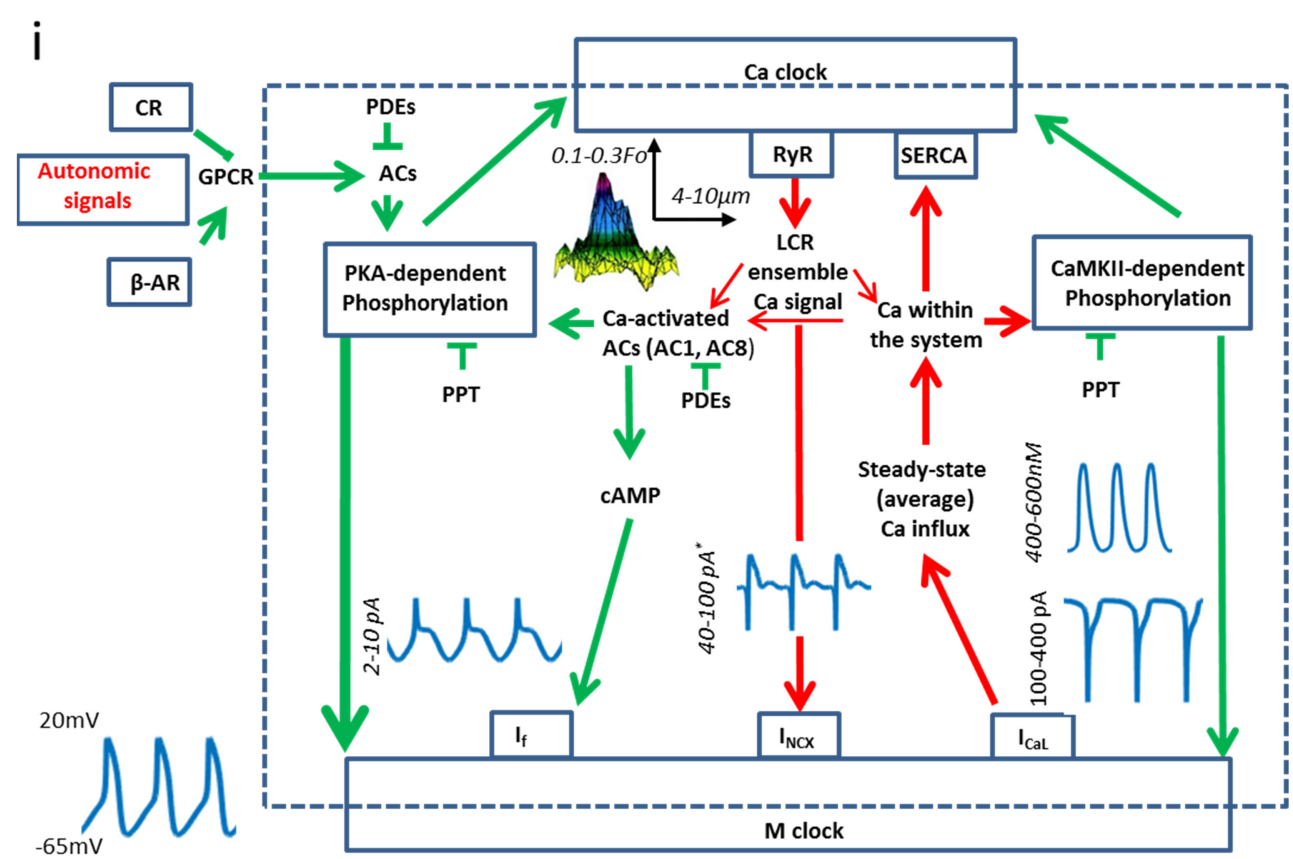

ii
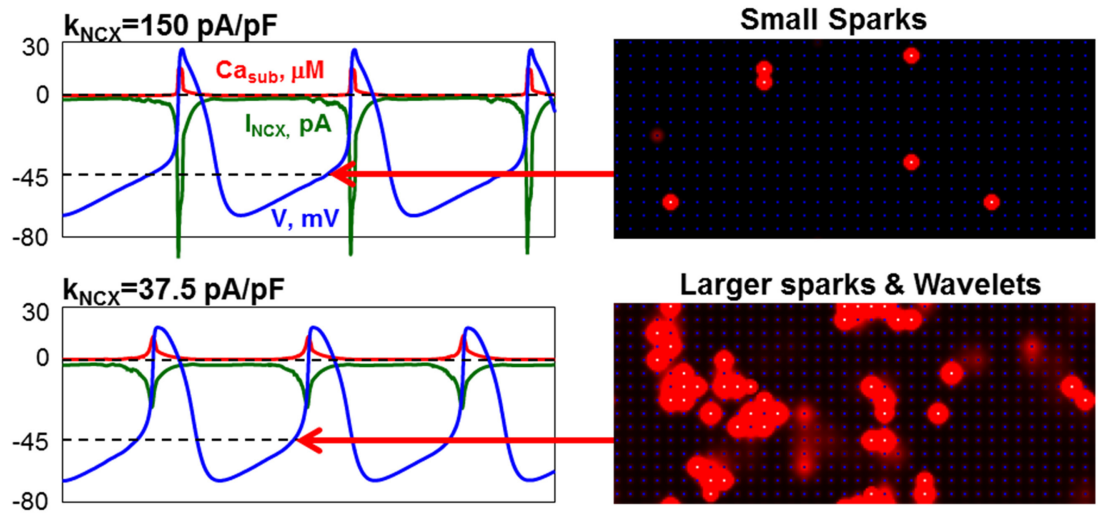

Larger sparks \& Wavelets
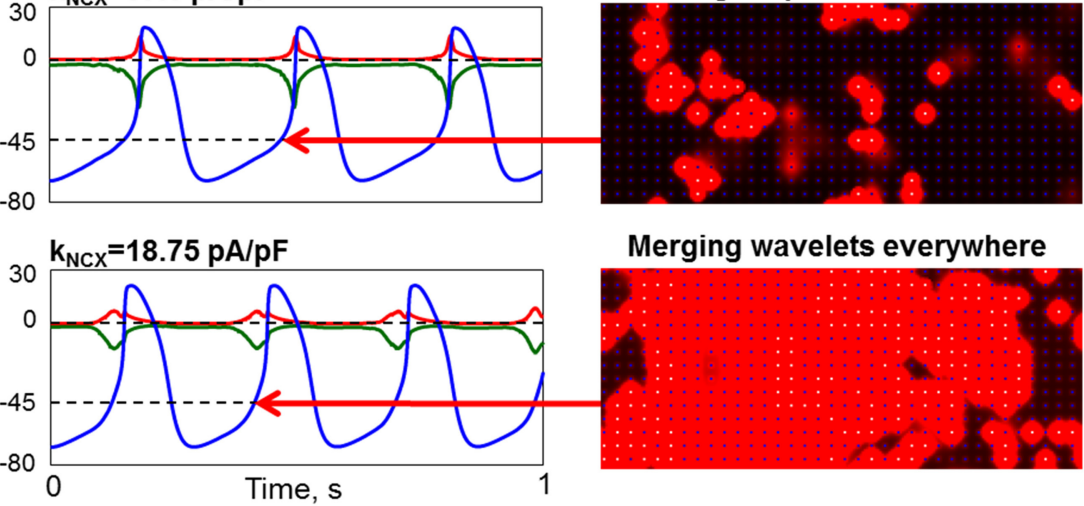

Merging wavelets everywhere
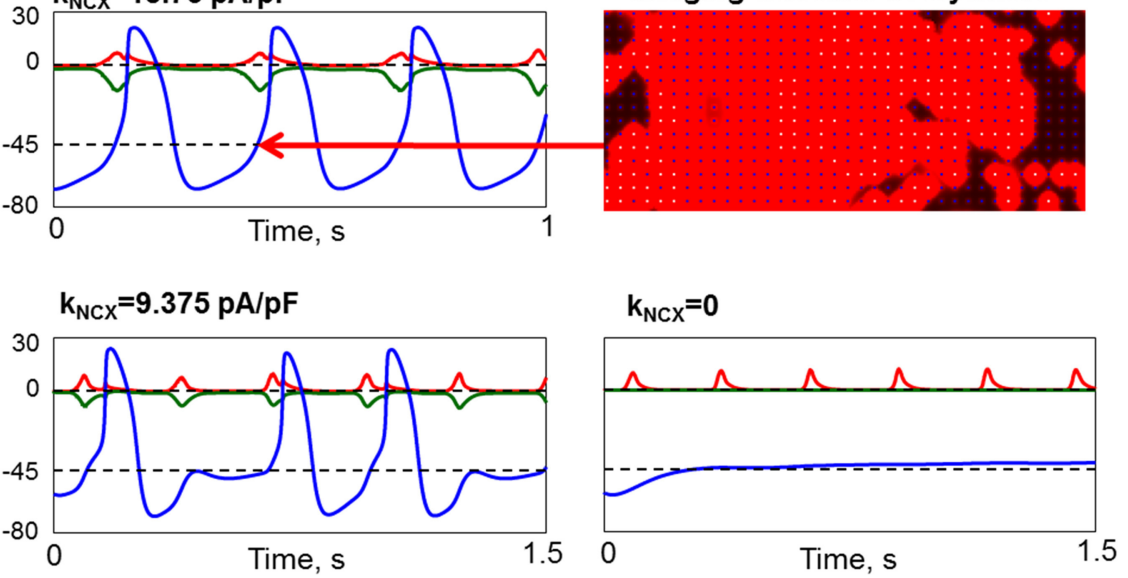

FIGURE 1 | Coupled-clock molecules and brain-heart signaling receptors that drive basal automaticity of SANC. (i) The neurotransmitters noradrenaline (NE) and acetylcholine (ACh) released from sympathetic or parasympathetic nerve terminals bind to $\beta$-adrenergic receptors ( $\beta$-AR) or cholinergic receptors (CR), respectively. Autonomic receptor signaling couples to G-proteins (GPCR) and leads to modulation of the same coupled-clock molecules that drive basal automaticity of SANC.

(Continued) 


\section{FIGURE 1 | Continued}

Basal $\mathrm{Ca}^{2+}$-calmodulin activation of adenylyl cyclases (AC), which produce cAMP-PKA-dependent phosphorylation and calmodulin-dependent kinase II (CaMKII)-dependent phosphorylation signaling. cAMP positively shifts the f-channel activation curve. Phosphodiesterases (PDE) degrade cAMP production, while protein phosphatase (PPT) degrades phosphorylation activity. PKA and CaMKII signaling phosphorylate $\mathrm{SR} \mathrm{Ca}^{2+}$ cycling proteins (RyR, phospholamban, which bind to and inhibit SERCA) and surface membrane ion channels. ${ }^{*}$ The values are for INCX amplitude (within the cycle) achieved during systole, however the diastolic amplitude is almost an order of magnitude lower. (ii) Numerical model simulations of membrane potential

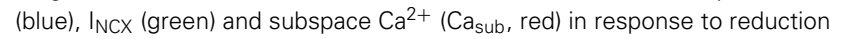
in NCX expression. As NCX expression becomes reduced the spread of $\mathrm{Ca}^{2+}$ release between RyRs via $\mathrm{Ca}^{2+}$ induced $\mathrm{Ca}^{2+}$ release is enhanced, resulting in a more effective activation of the remaining NCX molecules by LCRs. Further reduction in NCX uncoupled (partially or fully) LCR from AP generation. Specifically, NCX current becomes too small to depolarize the membrane and AP generation fail (modified from Maltsev et al., 2013). (i.e., surface membrane), hierarchical brain-heart signaling (i.e., neurotransmitter or hormonal stimulation of surface membrane receptors) and modulated by environmental mechanical, chemical and thermal factors (Figure 1). The SR rhythmically discharges local diastolic $\mathrm{Ca}^{2+}$ releases (LCRs) beneath the cell surface membrane; LCRs activate an inward $\mathrm{Na}^{+} / \mathrm{Ca}^{2+}$ exchange (NCX) current that prompts the surface membrane clock (M clock), an ensemble of sarcolemmal electrogenic molecules, to generate an AP. LCR Ca ${ }^{2+}$ signal is regulated not only by the SR $\mathrm{Ca}^{2+}$ pumping, which depends not only on SR proteins (phospholamban and RyR), and their phosphorylation status, but also by functions and phosphorylation status of M-clock proteins, e.g., L-type $\mathrm{Ca}^{2+}$ channels that regulate cell $\mathrm{Ca}^{2+}$ available for SR pumping, i.e., $\mathrm{Ca}^{2+}$-clock's substrate or "fuel." LCR signals affect $\mathrm{Ca}^{2+}$-dependent electrogenic processes (such as $\mathrm{Na}^{+} / \mathrm{Ca}^{2+}$ exchange) and voltage-dependent $\mathrm{Ca}^{2+}$ fluxes (such as via $\mathrm{Ca}^{2+}$ dependent inactivation of L-type $\mathrm{Ca}^{2+}$ channels). Therefore, the amplitude and phase of the LCR $\mathrm{Ca}^{2+}$ signal sensed by M-clock proteins reports the degree of synchronization and coupling of pacemaker mechanisms of both clocks, i.e., a stronger, more synchronized, and earlier LCR signal to M-clock proteins reports more efficient clock coupling that results in further shortening of the AP-beating interval (BI).

The coupled-clock theory predicts that extremely complex crosstalk between the two clocks via signaling pathways can amplify each other via secondary (indirect) mechanisms (reviewed in Maltsev and Lakatta, 2012), e.g., the crosstalk determines cell $\mathrm{Ca}^{2+}$ which, in turn, activates calmodulinadenylyl cyclase (AC)-dependent protein kinase A (PKA) and $\mathrm{Ca}^{2+} /$ calmodulin-dependent protein kinase II (CaMKII) (Mattick et al., 2007; Younes et al., 2008; Yaniv et al., 2013b). These phosphorylation signaling cascades act on both SR (phospholamban and RyR) and M-clock proteins (such as $\mathrm{L}$ type $\mathrm{Ca}^{2+}$ channels and $\mathrm{K}^{+}$channels). Numerical model simulations predict that the diastolic LCR signal is also regulated both by the level of $\mathrm{Ca}^{2+}$ cycling, and by the phosphorylation states of coupledclock proteins (Maltsev and Lakatta, 2009; Yaniv et al., 2013a; Stern et al., 2014). Indeed, the LCR period (i.e., the time period of an LCR occurrence following the prior AP) reports the degree of synchronization of the coupled-clock mechanisms (Monfredi et al., 2013; Yaniv et al., 2013a, 2014b). Thus, during higher degrees of clock coupling AP BI and LCR period are shorter and vice versa. LCRs affect $\mathrm{Ca}^{2+}$ dependent mechanisms, specifically NCX, whereas the M-clock effects $\mathrm{Ca}^{2+}$ clock primarily via $\mathrm{I}_{\mathrm{Ca}, \mathrm{L}}$. Phosphorylation signaling acts on both clocks and a decrease in its level is correlated with a decrease in the degree of synchronization of the coupled-clock mechanisms (Yaniv et al., 2014b). Numerical evidence has shown the essential roles of both mechanisms to couple clock functions (see below).

Although majority of the original experiments supporting the coupled-clock concept were performed in rabbit pacemaker cells, recent experimental results from mouse genetic models have clarified the role of many coupled-clock components: NCX (Groenke et al., 2013; Herrmann et al., 2013), I (Ludwig et al., 1998; Stieber et al., 2004; Herrmann et al., 2007), T-type channels (Mesirca et al., 2014), G protein signaling (Yang et al., 2010; Wydeven et al., 2014), Cav1.3 (Christel et al., 2012), CaMKII activity (Zhang et al., 2005; Gao et al., 2011) and ankyrin-B function (Le Scouarnec et al., 2008). In this regard mice pacemaker cell model provides evidence for the role of TRP channels and IP3 receptors; TRPM4 channels conduct both $\mathrm{Na}^{+}$and $\mathrm{K}^{+}$, but does not conduct $\mathrm{Ca}^{2+}$. TRPM has been recognized as the $\mathrm{Ca}^{2+}$ activated nonselective cation channel (Demion et al., 2007) and its role in modulating AP firing rate has been shown recently (Hof et al., 2013). Specifically, TRPM7 has been shown as a dominant channel-kinase that influences diastolic membrane depolarization (Sah et al., 2013). 1,4,5-trisphosphate (IP3) receptors exist in mice pacemaker and can release $\mathrm{Ca}^{2+}$ from the SR contributing to the intracellular $\mathrm{Ca}^{2+}$ that couples both clocks (Ju et al., 2011, 2012). Note that the relevant of studies in mice to other species with much lower hear rate has to be proven.

\section{MECHANISMS INTRINSIC TO PACEMAKER CELLS CONTROL AP FIRING RATE AND RHYTHM}

The spontaneous AP BI of single isolated pacemaker cells and SAN tissue are roughly periodic, i.e., this period varies on a beatto-beat basis (Verheijck et al., 1998; Rocchetti et al., 2000; Zaza and Lombardi, 2001; Monfredi et al., 2011; Papaioannou et al., 2013; Yaniv et al., 2014a,b). Recent experimental evidence shows that the degree of clock coupling determines not only the average pacemaker cell AP BI, but also the AP beating interval variability (BIV) (Yaniv et al., 2014b) (Figure 2). LCR periods vary among individual LCRs occurring within each spontaneous AP cycle and, similar to AP BI variability, among different cycles (Monfredi et al., 2013; Stern et al., 2014; Yaniv et al., 2014b). The ensemble LCR period and size report the extent of synchronization of the coupled-clock mechanisms. Indeed, the variability in the average LCR period in each cycle is correlated with the variability of the AP BI (Monfredi et al., 2013; Yaniv et al., 2014b) (Figure 2) and beat-to-beat variation in periodicity of LCRs is associated with intrinsic variations of spontaneous AP BI (Monfredi et al., 2013). Based on the coupled-clock theory, the stochasticity of LCR $\mathrm{Ca}^{2+}$ signal depends on stochastic RyR activation (Stern et al., 2014) and the cell $\mathrm{Ca}^{2+}$ balance that in turn is determined, in part, by 

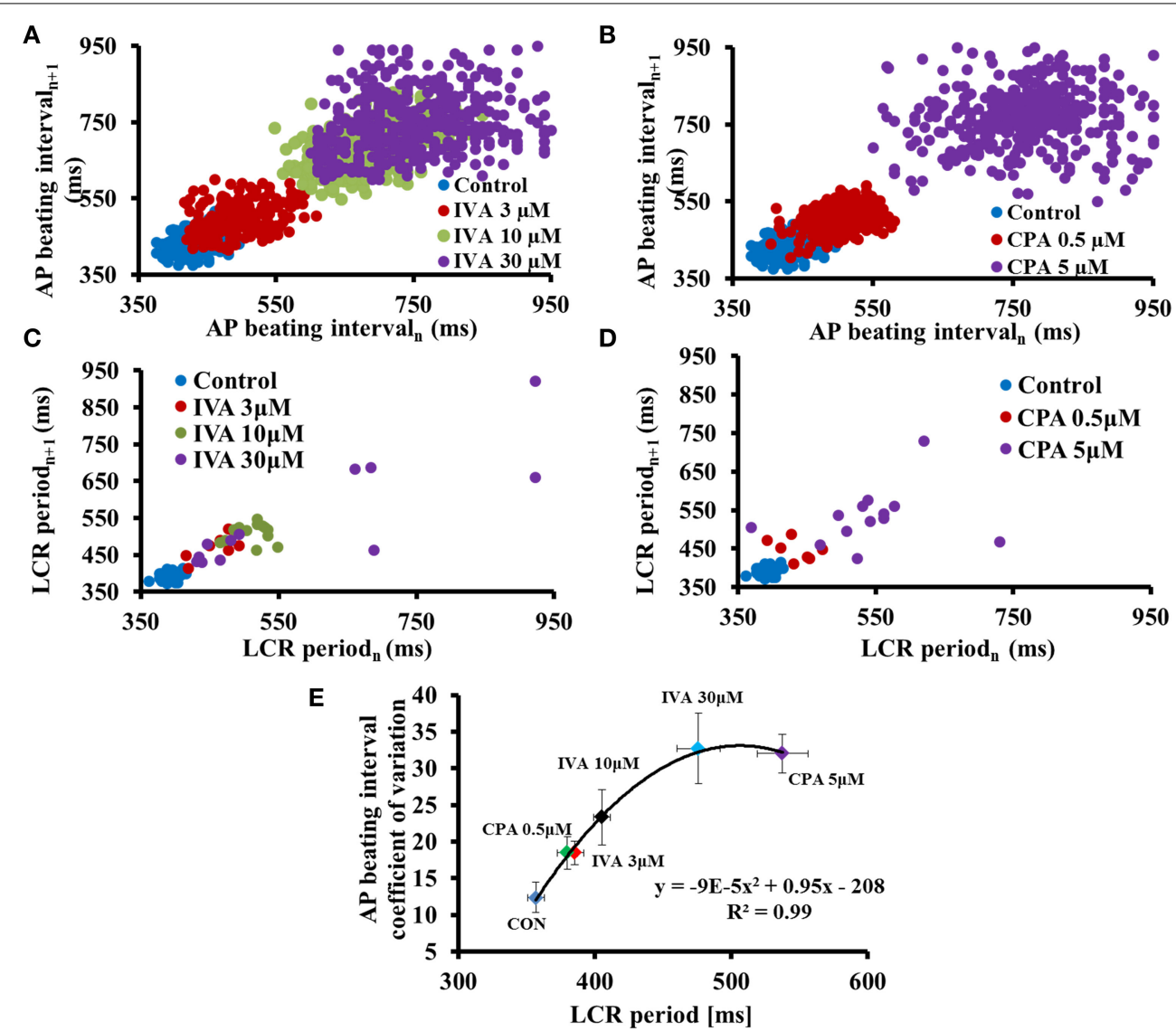

FIGURE 2 | Reduced synchronization of coupled-clock mechanisms prolongs AP beating interval variability and LCR period variability. To unravel clock-crosstalk effects on AP BIV and LCR period variability, clock function was perturbed by directly inhibiting either the $\mathrm{M}$ or $\mathrm{Ca}^{2+}$-clock. To inhibit the M-clock, a range of concentrations of ivabradine (IVA), an If inhibitor were employed. To inhibit the $\mathrm{Ca}^{2+}$-clock, a range of concentrations of cyclopiazonic acid (CPA), a SR $\mathrm{Ca}^{2+}$ pump inhibitor were employed. Poincare plots of the beating interval in control and in response to (A) IVA or (B) CPA. Poincaré plots of LCR period in control and in response to (C) IVA or (D) CPA. (E) The relationship between the average AP BIV, quantified by coefficient of variation to the LCR period prior to and in response to different concentrations of either IVA or CPA (modified from Yaniv et al., 2014b). stochastic sarcolemmal ion channel openings and closings. The occurrence of an AP synchronizes global stochastic RyR activation, and therefore synchronizes subsequent generation of LCRs by the RyRs during the diastolic depolarization phase. The amplitude of LCR $\mathrm{Ca}^{2+}$ signal to M-clock proteins reports the efficiency of clock coupling, i.e., a weaker LCR signal to M-clock proteins reports less-efficient clock coupling. At steady state, increase in LCR variability is also linked to reduced peak ensemble LCR $\mathrm{Ca}^{2+}$ signal amplitude that occurs later in diastole (i.e., prolonged next AP ignition). Therefore, the extent to which intrinsic clock mechanisms regulates the coupled-clock determines both the steady state $\mathrm{BI}$ and BIV in isolated pacemaker cells.

\section{BRAIN MODULATION OF THE INTRINSIC MECHANISMS TO PACEMAKER CELL}

The brain imparts flexibility to intrinsic clock mechanisms by concomitant activation of two types of receptors: $\beta$-adrenergic receptors $(\beta-A R)$ that increases the heart rate and cholinergic receptors $(\mathrm{CR})$ that decreases the heart rate (Figure 1). In humans, change in receptor activation can change the heart rate from 60 to $240 \mathrm{bpm}$. Receptor stimulation within pacemaker cells couples the signaling of G-proteins to AC (likely type 5 or 6), leading to activation or suppression of PKA and CaMKII- dependent phosphorylation signaling to key functional proteins of both clocks that regulate pacemaker cell automaticity. Therefore, both brain-heart signaling and intrinsic-pacemaker cell mechanisms signal to the very same nodes (coupling factors, such as PKA and CaMKII, Figure 1) of the coupled-clock system

$\beta$-AR stimulation in single pacemaker cell not only markedly decreases the average AP BI, but also decreases the AP BIV indices (Zaza et al., 1996; Yaniv et al., 2014a) and increases the likelihood that pacemaker cell BIs exhibit fractal-like behavior (Yaniv et al., 2014a). $\beta$-AR stimulation increases the efficiency of the coupled-clock system (Yaniv et al., 2014a). A reduction in LCR variability is associated with increased peak ensemble LCR $\mathrm{Ca}^{2+}$ signal that occurs early in diastole (Monfredi et al., 2012; Yaniv et al., 2014b). $\beta$-AR stimulation decreases the beating-interval entropy, which in isolated pacemaker cells is within a range that has been documented in random systems. Therefore, $\beta$-AR stimulation confers beating interval complexity. CR stimulation, in 
contrast, not only markedly increases both the average AP BI and AP BIV indices of single isolated pacemaker cells, but also impairs beating interval complexity (Rocchetti et al., 2000; Zaza and Lombardi, 2001; Yaniv et al., 2014a). Therefore, CR stimulation reduces the efficiency of the clocks coupling (Yaniv et al., 2014a).

\section{THE COUPLED CLOCK SYSTEM OPERATES ON A BEAT-TO-BEAT BASIS}

While a mutual entrainment exists between the $\mathrm{M}$ and $\mathrm{Ca}^{2+}$ clocks, it was not known if this entrainment happens on a beat-tobeat basis. Patch clamp experiments in single SAN cells (SANC) appeared to show a minor role of $\mathrm{Ca}^{2+}$ dynamics in SANC function (Himeno et al., 2011). The spontaneous AP rate was little changed when BAPTA, a $\mathrm{Ca}^{2+}$ chelator, was acutely infused via a patch pipette into SANC. These results, however, were later refuted on technical grounds (Maltsev et al., 2011b), taking into account that whole cell configuration generates artificial leak currents that substitute the pacemaker currents.

In contrast to these results, three sets of experiments that rapidly perturb the $\mathrm{Ca}^{2+}$-clock in intact SANC have demonstrated the time-dependent beat-to-beat mutual entrainment between the two clocks. In the first experiment set single isolated rabbit SANC were loaded with a caged $\mathrm{Ca}^{2+}$ buffer, NP-EGTA, which induced an increase in AP BI and markedly suppressed LCR $\mathrm{Ca}^{2+}$ signals and uncoupled them from AP generation (Yaniv et al., 2011). Flash photolysis released $\mathrm{Ca}^{2+}$ from the caged compound, immediately restored $\mathrm{Ca}^{2+}$ dynamics and within the same AP cycle. In the second experiment set low concentrations of caffeine (2-4 mM) were rapidly applied to single isolated rabbit SANC (Yaniv et al., 2013c). Caffeine induced immediate $\mathrm{Ca}^{2+}$ release from the SR and immediately reduced the AP cycle. Lastly, in each given cycle the phase of the entire ensemble LCR signal (i.e. the average LCR period) is linked to that length of that cycle (Monfredi et al., 2013). Therefore, mutual clock entrainment exists on a beat-to-beat basis.

\section{NUMERICAL MODELING: FROM ONE CLOCK TO ONE COUPLED SYSTEM}

The shift from numerical models that describe only the M-clock to the new paradigm of the coupled-clock system occurred in several stages, as new data became available and new respective models were generated. The first model that attempted to explore the importance of $\mathrm{Ca}^{2+}$ levels in sub-membrane space with respect to M-clock molecules (specifically the NCX) was formulated by Kurata (Kurata et al., 2002). While this modeling approach reproduced, in part, bradycardic effects of intracellular $\mathrm{Ca}^{2+}$ buffering reported earlier in experimental studies (Vinogradova et al., 2000), it remained essentially naive and did not embrace a numerical mechanism of $\mathrm{Ca}^{2+}$ "clocking."

The coupled-clock mechanism was established in 2009 (Maltsev and Lakatta, 2009) by a detailed sensitivity analysis of a new pacemaker cell model originated from Kurata et al. model (Kurata et al., 2002). This new model (often referred to as Maltsev-Lakatta model or ML model) included, in addition to the formulations of the M-clock molecules, new formulations of the SR function, predicting oscillatory LCR ensemble $\mathrm{Ca}^{2+}$ signals, driven by SR $\mathrm{Ca}^{2+}$ pumping and $\mathrm{Ca}^{2+}$ release kinetics. The two clocks are coupled in the ML model via multiple coupling factors, such as $\mathrm{Ca}^{2+}$, cAMP, PKA, and CaMKII. Therefore, the SR $\mathrm{Ca}^{2+}$. clock not only modulates the M-clock, but the M-clock, in turn, also affects $\mathrm{Ca}^{2+}$-clock.

This coupled-clock model made important predictions that prompted further studies:

(i) Importance of $\mathrm{SR} \mathrm{Ca}^{2+}$ refilling kinetics for $\mathrm{AP}$ firing rate (confirmed experimentally in Vinogradova et al., 2010)

(ii) Both "biophysical" and "biochemical" entrainments are required to explain complex effects of clock's-specific perturbations (Yaniv et al., 2013a), e.g., by either ivabradine, a specific $\mathrm{I}_{\mathrm{f}}$ blocker or cyclopiazonic acid, a specific SR $\mathrm{Ca}^{2+}$. ATPase (SERCA) pump blocker. It was shown that a direct perturbation of one clock inevitably affects the other due to subsequent indirect effects, resulting in mutual entrainment, i.e., clocks coupling, predicted by the theory.

(iii) The entire range of physiological chronotropic modulation of SANC by activation of $\beta$-AR or CR can be achieved in simulations of the ML model only when their effect on both sarcolemmal ion channels and SR $\mathrm{Ca}^{2+}$ pumping capability are taking into account (Maltsev and Lakatta, 2010).

Of note, other numerical models with unbalanced mutual entrainment between the clocks have been developed (Zhang et al., 2000; Butters et al., 2010; Inada et al., 2014). Specifically, recent numerical model has applied to explain the relationship between heart rate and rhythm (Monfredi et al., 2014). Although these models have some merit and can explain some experimental results, the real test or value of numerical models is to reproduce the experimental data of mutual entrainment on a beat-to-beat basis, which these simplistic models cannot achieve.

Mutual entrainment of the $\mathrm{Ca}^{2+}$ and M-clock exists on a beat-to-beat basis (see above). Numerical simulations, using a modified ML "coupled-clock" model, faithfully reproduced experimentally reported prolongation of the AP BI and associated dys-rhythmic spontaneous beating in the presence of cytosolic $\mathrm{Ca}^{2+}$ buffering (Yaniv et al., 2013c). However, three contemporary numerical models (Kurata et al., 2002; Severi et al., 2012) and the original ML model (Maltsev and Lakatta, 2009), failed to reproduce the effects of severe and acute perturbations of the system, e.g., the transient reduction in AP BI induced by both caffeine and flash-induced $\mathrm{Ca}^{2+}$ release (Yaniv et al., 2013c).

The modified ML model provided new insights into the nature of beat-to-beat clock entrainment (Yaniv et al., 2013c): (i) The major mechanisms that couple the beat-to-beat changes in $\mathrm{Ca}^{2+}$. clock to M-clock mechanisms is LCR-activation of the NCX current. (ii) The systems has a "memory" for several beats: after flash-induced $\mathrm{Ca}^{2+}$ release the temporal rate increase are linked to changes in $\mathrm{Ca}^{2+}$ available for pumping into the SR that ultimately results in a temporal increase in diastolic NCX current driving the AP firing rate increase.

Recognition of the limitations of the traditional common-pool model approach have led to novel pacemaker cell models featuring local $\mathrm{Ca}^{2+}$ control mechanisms (for review see Maltsev et al., 2014). Thus, newer local control models are more accurate vs. old 
common pool models: the scale of amplitudes for $\mathrm{Ca}^{2+}$ dynamics attained locally is higher by as much as two orders of magnitude vs. that predicted by the old models. The common pool models also lack crucial mechanisms of $\mathrm{Ca}^{2+}$ dynamics, such as diffusionreaction for the $\mathrm{Ca}^{2+}$ release, local $\mathrm{Ca}^{2+}$ pumping and local NCX activity. The first model (Maltsev et al., 2011a) generated LCRs via stochastic recruitment of the neighboring CRUs. This model was later updated to include LCR regulation by local interactions with M-clock driving by NCX (Maltsev et al., 2013). The model predicted that when the RyR sensitivity is very high or the NCX density is low, synchronization between the clocks is lost, leading to dysrhythmic AP BI (Maltsev et al., 2013). The most recent and advanced formulations of local $\mathrm{Ca}^{2+}$ mechanisms in pacemaker cells include stochastic gating of individual RyR and L-type $\mathrm{Ca}^{2+}$ channels in $\mathrm{Ca}^{2+}$ diffusion and buffering in 3 dimensions (Stern et al., 2014). The model succeeded in reproducing observed propagating local $\mathrm{Ca}^{2+}$ releases and realistic pacemaker rates only when RyR locations were assigned taking into account irregular, hierarchical distribution of RyR clusters (small and large) observed in $3 \mathrm{D}$ confocal scan sections of immunofluorescence staining.

A new generation of model featuring local $\mathrm{Ca}^{2+}$ dynamics within a coupled-clock system is being developed and will provide novel insights into pacemaker cell mechanisms. A "multiscale" modeling has been put forward by James Weiss group that modeled $\mathrm{Ca}^{2+}$ dynamics in cardiac cells (Qu et al., 2011). This approach develops formulations for $\mathrm{Ca}^{2+}$ dynamics at each level or scale of integration. This, in turn, represents a substantial challenge and requires a detailed knowledge of the previous layer to avoid simply phenomenological or arbitrary descriptions. In this regard, the recent Stern et al. model (2014), describing states of all individual RyR and L-type $\mathrm{Ca}^{2+}$ channel will be helpful to approach the next level integration at the whole cell $\mathrm{Ca}^{2+}$ dynamics.

\section{SUMMARY}

Mechanisms intrinsic to pacemaker cells and their modulation by the brain-heart receptor signaling determine both the heart rate and heart rate variability. Crosstalk exists between $M$ and $\mathrm{Ca}^{2+}$-clock and the tightness of this crosstalk, informed by the LCR period, determines the rate and rhythm of spontaneous AP generation. Indeed, both theoretical and experimental evidence has mounted to indicate that this clock "crosstalk" operates on a beat-to-beat basis.

In the level of pacemaker cells, future experiments are needed to quantify beat-to-beat regulation of cAMP/PKA signaling that drives clock coupling in order to speculate whether they take part in the mutual entrainment between the clocks in a beat-to-beat basis. Moreover, the extent to which reduction in synchronization of intrinsic clock periods within pacemaker cells is associated with cardiac diseases and aging awaits further elucidation. Finally, novel mathematical models that quantify not only the average AP firing, but also determine its rhythm await further development.

Similar contribution of coupled-clock mechanisms to membrane firing rate and rhythm can exist in other heart tissues. In this regard, crosstalk between $\mathrm{Ca}^{2+}$ leak from the SR and NCX current can trigger an arrhythmia in atrial fibrillation patients
(Lakatta and Guarnieri, 1993; Voigt et al., 2014). Future work is needed to determine if pacemaking-like behavior exist in atrial cell during normal and abnormal conditions.

\section{ACKNOWLEDGMENTS}

This research was partially supported by the Intramural Research Program of the NIH, National Institute on Aging, by Technion V.P.R Fund-Mallat Family Research Fund (YY) and by NSFC-ISF joint research program, No. 398/14 (YY).

\section{REFERENCES}

Butters, T. D., Aslanidi, O. V., Inada, S., Boyett, M. R., Hancox, J. C., Lei, M., et al. (2010). Mechanistic links between $\mathrm{Na}^{+}$channel (SCN5A) mutations and impaired cardiac pacemaking in sick sinus syndrome. Circ. Res. 107, 126-137. doi: 10.1161/CIRCRESAHA.110.219949

Christel, C. J., Cardona, N., Mesirca, P., Herrmann, S., Hofmann, F., Striessnig, J., et al. (2012). Distinct localization and modulation of Cav1.2 and Cav1.3 Ltype $\mathrm{Ca}^{2+}$ channels in mouse sinoatrial node. J. Physiol. 590, 6327-6342. doi: 10.1113/jphysiol.2012.239954

Demion, M., Bois, P., Launay, P., and Guinamard, R. (2007). TRPM4, a $\mathrm{Ca} 2+$-activated nonselective cation channel in mouse sino-atrial node cells. Cardiovasc. Res. 73, 531-538. doi: 10.1016/j.cardiores.2006.11.023

Gao, Z., Singh, M. V., Hall, D. D., Koval, O. M., Luczak, E. D., Joiner, M. L., et al. (2011). Catecholamine-independent heart rate increases require $\mathrm{Ca}^{2+} /$ calmodulin-dependent protein kinase II. Circ. Arrhythm. Electrophysiol. 4, 379-387. doi: 10.1161/CIRCEP.110.961771

Groenke, S., Larson, E. D., Alber, S., Zhang, R., Lamp, S. T., Ren, X., et al. (2013). Complete atrial-specific knockout of sodium-calcium exchange eliminates sinoatrial node pacemaker activity. PLOS ONE 8:e81633. doi: 10.1371/journal.pone.0081633

Herrmann, S., Lipp, P., Wiesen, K., Stieber, J., Nguyen, H., Kaiser, E., et al. (2013) The cardiac sodium-calcium exchanger NCX1 is a key player in the initiation and maintenance of a stable heart rhythm. Cardiovasc. Res. 99, 780-788. doi: $10.1093 / \mathrm{cvr} / \mathrm{cvt} 154$

Herrmann, S., Stieber, J., Stockl, G., Hofmann, F., and Ludwig, A. (2007). HCN4 provides a 'depolarization reserve' and is not required for heart rate acceleration in mice. EMBO J. 26, 4423-4432. doi: 10.1038/sj.emboj. 7601868

Himeno, Y., Toyoda, F., Satoh, H., Amano, A., Cha, C. Y., Matsuura, H., et al. (2011). Minor contribution of cytosolic $\mathrm{Ca}^{2+}$ transients to the pacemaker rhythm in guinea pig sinoatrial node cells. Am. J. Physiol. Heart Circ. Physiol. 300, H251-H261. doi: 10.1152/ajpheart.00764.2010

Hof, T., Simard, C., Rouet, R., Salle, L., and Guinamard, R. (2013). Implication of the TRPM4 nonselective cation channel in mammalian sinus rhythm. Heart Rhythm 10, 1683-1689. doi: 10.1016/j.hrthm.2013.08.014

Inada, S., Zhang, H., Tellez, J. O., Shibata, N., Nakazawa, K., Kamiya, K., et al. (2014). Importance of gradients in membrane properties and electrical coupling in sinoatrial node pacing. PLoS ONE 9:e94565. doi: 10.1371/journal.pone.0094565

Ju, Y. K., Liu, J., Lee, B. H., Lai, D., Woodcock, E. A., Lei, M., et al. (2011). Distribution and functional role of inositol 1,4,5-trisphosphate receptors in mouse sinoatrial node. Circ. Res. 109, 848-857. doi: 10.1161/CIRCRESAHA.111.243824

Ju, Y. K., Woodcock, E. A., Allen, D. G., and Cannell, M. B. (2012). Inositol 1,4,5-trisphosphate receptors and pacemaker rhythms. J. Mol. Cell. Cardiol. 53, 375-381. doi: 10.1016/j.yjmcc.2012.06.004

Kurata, Y., Hisatome, I., Imanishi, S., and Shibamoto, T. (2002). Dynamical description of sinoatrial node pacemaking: improved mathematical model for primary pacemaker cell. Am. J. Physiol. Heart Circ. Physiol. 283, H2074-H2101. doi: 10.1152/ajpheart.00900.2001

Lakatta, E. G., and Difrancesco, D. (2009). What keeps us ticking: a funny current, a calcium clock, or both? J. Mol. Cell. Cardiol. 47, 157-170. doi: 10.1016/j.yjmcc.2009.03.022

Lakatta, E. G., and Guarnieri, T. (1993). Spontaneous myocardial calcium oscillations: are they linked to ventricular fibrillation? J. Cardiovasc. Electrophysiol. 4, 473-489. doi: 10.1111/j.1540-8167.1993.tb01285.x 
Lakatta, E. G., Maltsev, V. A., and Vinogradova, T. M. (2010). A coupled SYSTEM of intracellular $\mathrm{Ca}^{2+}$ clocks and surface membrane voltage clocks controls the timekeeping mechanism of the heart's pacemaker. Circ. Res. 106, 659-673. doi: 10.1161/CIRCRESAHA.109.206078

Le Scouarnec, S., Bhasin, N., Vieyres, C., Hund, T. J., Cunha, S. R., Koval, O., et al. (2008). Dysfunction in ankyrin-B-dependent ion channel and transporter targeting causes human sinus node disease. Proc. Natl. Acad. Sci. U.S.A. 105, 15617-15622. doi: 10.1073/pnas.0805500105

Ludwig, A., Zong, X., Jeglitsch, M., Hofmann, F., and Biel, M. (1998). A family of hyperpolarization-activated mammalian cation channels. Nature 393, 587-591. doi: $10.1038 / 31255$

Maltsev, A. V., Maltsev, V. A., Mikheev, M., Maltseva, L. A., Sirenko, S. G., Lakatta, E. G., et al. (2011a). Synchronization of stochastic $\mathrm{Ca}^{(2)(+)}$ release units creates a rhythmic $\mathrm{Ca}^{(2)(+)}$ clock in cardiac pacemaker cells. Biophys. J. 100, 271-283. doi: 10.1016/j.bpj.2010.11.081

Maltsev, A. V., Yaniv, Y., Stern, M. D., Lakatta, E. G., and Maltsev, V. A. (2013). RyR-NCX-SERCA local cross-talk ensures pacemaker cell function at rest and during the fight-or-flight reflex. Circ. Res. 113, e94-e100. doi: 10.1161/CIRCRESAHA.113.302465

Maltsev, V. A., and Lakatta, E. G. (2009). Synergism of coupled subsarcolemmal $\mathrm{Ca}^{2+}$ clocks and sarcolemmal voltage clocks confers robust and flexible pacemaker function in a novel pacemaker cell model. Am. J. Physiol. Heart Circ. Physiol. 296, H594-H615. doi: 10.1152/ajpheart.01118.2008

Maltsev, V. A., and Lakatta, E. G. (2010). A novel quantitative explanation for the autonomic modulation of cardiac pacemaker cell automaticity via a dynamic system of sarcolemmal and intracellular proteins. Am. J. Physiol. Heart Circ. Physiol. 298, H2010-H2023. doi: 10.1152/ajpheart.00783.2009

Maltsev, V. A., and Lakatta, E. G. (2012). The funny current in the context of the coupled-clock pacemaker cell system. Heart Rhythm 9, 302-307. doi: 10.1016/j.hrthm.2011.09.022

Maltsev, V. A., and Lakatta, E. G. (2013). Numerical models based on a minimal set of sarcolemmal electrogenic proteins and an intracellular $\mathrm{Ca}^{(2+)}$ clock generate robust, flexible, and energy-efficient cardiac pacemaking. J. Mol. Cell. Cardiol. 59, 181-195. doi: 10.1016/j.yjmcc.2013.03.004

Maltsev, V. A., Vinogradova, T. M., and Lakatta, E. G. (2006). The emergence of a general theory of the initiation and strength of the heartbeat. J. Pharmacol. Sci. 100, 338-369. doi: 10.1254/jphs.CR0060018

Maltsev, V. A., Vinogradova, T. M., Stern, M. D., and Lakatta, E. G. (2011b). Letter to the editor: "Validating the requirement for beat-to-beat coupling of the $\mathrm{Ca} 2+$ clock and M clock in pacemaker cell normal automaticity." Am. J. Physiol. Heart Circ. Physiol. 300, H2323-H2324; author reply H2325-H2326.

Maltsev, V. A., Yaniv, Y., Maltsev, A. V., Stern, M. D., and Lakatta, E. G. (2014). Modern perspectives on numerical modeling of cardiac pacemaker cell. J. Pharmacol. Sci. 125, 6-38. doi: 10.1254/jphs.13R04CR

Mattick, P., Parrington, J., Odia, E., Simpson, A., Collins, T., and Terrar, D. (2007). $\mathrm{Ca}^{2+}$-stimulated adenylyl cyclase isoform $\mathrm{ACl}$ is preferentially expressed in guinea-pig sino-atrial node cells and modulates the $\mathrm{I}(\mathrm{f})$ pacemaker current. J. Physiol. 582, 1195-1203. doi: 10.1113/jphysiol.2007. 133439

Mesirca, P., Torrente, A. G., and Mangoni, M. E. (2014). T-type channels in the sino-atrial and atrioventricular pacemaker mechanism. Pflugers Arch. 466, 791-799. doi: 10.1007/s00424-014-1482-6

Monfredi, O. J., Maltseva, L. A., Boyett, M. R., Lakatta, E. G., and Maltsev, V. A. (2011). Stochastic beat-to-beat variation in periodicity of local calcium releases predicts intrinsic cycle length variability in single sinoatrial node cells. Biophys. J. 100, 558a. doi: 10.1016/j.bpj.2010.12.3243

Monfredi, O., Lakatta, E. G., and Maltsev, A. V. (2012). Synchronization of local calcium releases by beta-adrenergic stimulation in cardiac pacemaker cells. Biophys. J. 102, 103a. doi: 10.1016/j.bpj.2011.11.581

Monfredi, O., Lyashkov, A. E., Johnsen, A. B., Inada, S., Schneider, H., Wang, R., et al. (2014). Biophysical characterization of the underappreciated and important relationship between heart rate variability and heart rate. Hypertension 64, 1334-1343. doi: 10.1161/HYPERTENSIONAHA.114. 03782

Monfredi, O., Maltseva, L. A., Spurgeon, H. A., Boyett, M. R., Lakatta, E. G., and Maltsev, V. A. (2013). Beat-to-beat variation in periodicity of local calcium releases contributes to intrinsic variations of spontaneous cycle length in isolated single sinoatrial node cells. PLoS ONE 8:e67247. doi: 10.1371/journal.pone. 0067247
Noble, D., Noble, P. J., and Fink, M. (2010). Competing oscillators in cardiac pacemaking: historical background. Circ. Res. 106, 1791-1797. doi: 10.1161/CIRCRESAHA.110.218875

Papaioannou, V. E., Verkerk, A. O., Amin, A. S., and De Bakker, J. M. (2013). Intracardiac origin of heart rate variability, pacemaker funny current and their possible association with critical illness. Curr. Cardiol. Rev. 9, 82-96. doi: $10.2174 / 157340313805076359$

Qu, Z., Garfinkel, A., Weiss, J. N., and Nivala, M. (2011). Multi-scale modeling in biology: how to bridge the gaps between scales? Prog. Biophys. Mol. Biol. 107, 21-31. doi: 10.1016/j.pbiomolbio.2011.06.004

Rocchetti, M., Malfatto, G., Lombardi, F., and Zaza, A. (2000). Role of the input/output relation of sinoatrial myocytes in cholinergic modulation of heart rate variability. J. Cardiovasc. Electrophysiol. 11, 522-530. doi: 10.1111/j.15408167.2000.tb00005.x

Rosen, M. R., Nargeot, J., and Salama, G. (2012). The case for the funny current and the calcium clock. Heart Rhythm 9, 616-618. doi: 10.1016/j.hrthm.2011.10.008

Sah, R., Mesirca, P., Van Den Boogert, M., Rosen, J., Mably, J., Mangoni, M. E., et al. (2013). Ion channel-kinase TRPM7 is required for maintaining cardiac automaticity. Proc. Natl. Acad. Sci. U.S.A. 110, E3037-E3046. doi: 10.1073/pnas.1311865110

Severi, S., Fantini, M., Charawi, L. A., and Difrancesco, D. (2012). An updated computational model of rabbit sinoatrial action potential to investigate the mechanisms of heart rate modulation. J. Physiol. 590, 4483-4499. doi: 10.1113/jphysiol.2012.229435

Stern, M. D., Maltseva, L. A., Juhaszova, M., Sollott, S. J., Lakatta, E. G., and Maltsev, V. A. (2014). Hierarchical clustering of ryanodine receptors enables emergence of a calcium clock in sinoatrial node cells. J. Gen. Physiol. 143, 577-604. doi: 10.1085/jgp.201311123

Stieber, J., Hofmann, F., and Ludwig, A. (2004). Pacemaker channels and sinus node arrhythmia. Trends Cardiovasc. Med. 14, 23-28. doi: 10.1016/j.tcm.2003.09.006

Vassalle, M. (1995). The pacemaker current (I(f)) does not play an important role in regulating SA node pacemaker activity. Cardiovasc. Res. 30, 309-310. doi: 10.1016/0008-6363(95)00028-3

Verheijck, E. E., Wilders, R., Joyner, R. W., Golod, D. A., Kumar, R., Jongsma, H. J., et al. (1998). Pacemaker synchronization of electrically coupled rabbit sinoatrial node cells. J. Gen. Physiol. 111, 95-112. doi: 10.1085/jgp.111.1.95

Vinogradova, T. M., Brochet, D. X., Sirenko, S., Li, Y., Spurgeon, H., and Lakatta, E. G. (2010). Sarcoplasmic reticulum $\mathrm{Ca}^{2+}$ pumping kinetics regulates timing of local $\mathrm{Ca}^{2+}$ releases and spontaneous beating rate of rabbit sinoatrial node pacemaker cells. Circ. Res. 107, 767-775. doi: 10.1161/CIRCRESAHA.110. 220517

Vinogradova, T. M., Zhou, Y. Y., Bogdanov, K. Y., Yang, D., Kuschel, M., Cheng, H., et al. (2000). Sinoatrial node pacemaker activity requires $\mathrm{Ca}^{(2+)} /$ calmodulin-dependent protein kinase II activation. Circ. Res. 87, 760-767. doi: 10.1161/01.RES.87.9.760

Voigt, N., Heijman, J., Wang, Q., Chiang, D. Y., Li, N., Karck, M., et al. (2014). Cellular and molecular mechanisms of atrial arrhythmogenesis in patients with paroxysmal atrial fibrillation. Circulation 129, 145-156. doi: 10.1161/CIRCULATIONAHA.113.006641

Wilders, R. (2007). Computer modelling of the sinoatrial node. Med. Biol. Eng. Comput. 45, 189-207. doi: 10.1007/s11517-006-0127-0

Wydeven, N., Posokhova, E., Xia, Z., Martemyanov, K. A., and Wickman, K. (2014). RGS6, but not RGS4, is the dominant regulator of G protein signaling (RGS) modulator of the parasympathetic regulation of mouse heart rate. J. Biol. Chem. 289, 2440-2449. doi: 10.1074/jbc.M113.520742

Yang, J., Huang, J., Maity, B., Gao, Z., Lorca, R. A., Gudmundsson, H., et al. (2010). RGS6, a modulator of parasympathetic activation in heart. Circ. Res. 107, 1345-1349. doi: 10.1161/CIRCRESAHA.110.224220

Yaniv, Y., Ahmet, I., Liu, J., Lyashkov, A. E., Guiriba, T. R., Okamoto, Y., et al. (2014a). Synchronization of sinoatrial node pacemaker cell clocks and its autonomic modulation impart complexity to heart beating intervals. Heart Rhythm 11, 1210-1219. doi: 10.1016/j.hrthm.2014.03.049

Yaniv, Y., Lyashkov, A. E., Sirenko, S., Okamoto, Y., Guiriba, T. R., Ziman, B. D., et al. (2014b). Stochasticity intrinsic to coupled-clock mechanisms underlies beat-to-beat variability of spontaneous action potential firing in sinoatrial node pacemaker cells. J. Mol. Cell. Cardiol. 77, 1-10. doi: 10.1016/j.yjmcc.2014. 09.008

Yaniv, Y., Maltsev, V. A., Escobar, A. L., Spurgeon, H. A., Ziman, B. D., Stern, M. D., et al. (2011). Beat-to-beat $\mathrm{Ca}^{(2+)}$-dependent regulation of sinoatrial 
nodal pacemaker cell rate and rhythm. J. Mol. Cell. Cardiol. 51, 902-905. doi: 10.1016/j.yjmcc.2011.08.029

Yaniv, Y., Sirenko, S., Ziman, B. D., Spurgeon, H. A., Maltsev, V. A., and Lakatta, E. G. (2013a). New evidence for coupled clock regulation of the normal automaticity of sinoatrial nodal pacemaker cells: bradycardic effects of ivabradine are linked to suppression of intracellular $\mathrm{Ca}^{(2)(+)}$ cycling. J. Mol. Cell. Cardiol. 62, 80-89. doi: 10.1016/j.yjmcc.2013.04.026

Yaniv, Y., Spurgeon, H. A., Ziman, B. D., and Lakatta, E. G. (2013b). $\mathrm{Ca}^{(2)+} /$ calmodulin-dependent protein kinase II (CaMKII) activity and sinoatrial nodal pacemaker cell energetics. PLoS ONE 8:e57079. doi: 10.1371/journal.pone.0057079

Yaniv, Y., Stern, M. D., Lakatta, E. G., and Maltsev, V. A. (2013c). Mechanisms of beat-to-beat regulation of cardiac pacemaker cell function by $\mathrm{Ca}^{(2)(+)}$ cycling dynamics. Biophys. J. 105, 1551-1561. doi: 10.1016/j.bpj.2013.08.024

Younes, A., Lyashkov, A. E., Graham, D., Sheydina, A., Volkova, M. V., Mitsak, M., et al. (2008). $\mathrm{Ca}^{(2+)}$-stimulated basal adenylyl cyclase activity localization in membrane lipid microdomains of cardiac sinoatrial nodal pacemaker cells. J. Biol. Chem. 283, 14461-14468. doi: 10.1074/jbc.M707540200

Zaza, A., and Lombardi, F. (2001). Autonomic indexes based on the analysis of heart rate variability: a view from the sinus node. Cardiovasc. Res. 50, 434-442. doi: 10.1016/S0008-6363(01)00240-1

Zaza, A., Robinson, R. B., and Difrancesco, D. (1996). Basal responses of the Ltype $\mathrm{Ca}^{2+}$ and hyperpolarization-activated currents to autonomic agonists in the rabbit sino-atrial node. J. Physiol. 491(Pt 2), 347-355. doi: 10.1113/jphysiol.1996.sp021220
Zhang, H., Holden, A. V., Kodama, I., Honjo, H., Lei, M., Varghese, T., et al. (2000). Mathematical models of action potentials in the periphery and center of the rabbit sinoatrial node. Am. J. Physiol. Heart Circ. Physiol. 279, H397-H421.

Zhang, R., Khoo, M. S., Wu, Y., Yang, Y., Grueter, C. E., Ni, G., et al. (2005). Calmodulin kinase II inhibition protects against structural heart disease. Nat. Med. 11, 409-417. doi: 10.1038/nm1215

Conflict of Interest Statement: The authors declare that the research was conducted in the absence of any commercial or financial relationships that could be construed as a potential conflict of interest.

Received: 30 November 2014; paper pending published: 20 December 2014; accepted: 17 January 2015; published online: 13 February 2015.

Citation: Yaniv Y, Lakatta EG and Maltsev VA (2015) From two competing oscillators to one coupled-clock pacemaker cell system. Front. Physiol. 6:28. doi: 10.3389/fphys. 2015.00028

This article was submitted to Cardiac Electrophysiology, a section of the journal Frontiers in Physiology.

Copyright (c) 2015 Yaniv, Lakatta and Maltsev. This is an open-access article distributed under the terms of the Creative Commons Attribution License (CC BY). The use, distribution or reproduction in other forums is permitted, provided the original author(s) or licensor are credited and that the original publication in this journal is cited, in accordance with accepted academic practice. No use, distribution or reproduction is permitted which does not comply with these terms. 